1 Fundação Oswaldo Cruz (Fiocruz), Instituto de Tecnologia em Imunobiológicos (BioManguinhos) - Rio de Janeiro (RJ), Brasil. lyamendes@gmail.com

2 Fundação Oswaldo Cruz (Fiocruz), Escola Nacional de Saúde Pública Sergio Arouca (Ensp), Centro de Estudos em Saúde do Trabalhador e Ecologia Humana (Cesteh) - Rio de Janeiro (RJ), Brasil. teixeira.liliane@gmail.com

3 Fundação Oswaldo Cruz (Fiocruz), Escola Nacional de Saúde Pública Sergio Arouca (Ensp), Centro de Estudos em Saúde do Trabalhador e Ecologia Humana (Cesteh) - Rio de Janeiro (RJ), Brasil. renato.bonfatti@gmail.com

\section{As condições de saúde dos trabalhadores a partir dos exames periódicos de saúde}

\author{
The health conditions of workers from periodic health examinations
}

Eliane de Assis Mendes ${ }^{\mathbf{1}}$, Liliane Reis Teixeira ${ }^{2}$, Renato José Bonfatti ${ }^{\mathbf{3}}$

RESUMO Objetivou-se apresentar o perfil de saúde dos trabalhadores de uma unidade federal que realizaram os exames periódicos de saúde. Trata-se de um estudo descritivo e exploratório, no qual foram analisados 503 prontuários ocupacionais. Houve equilíbrio na participação por gênero e, proporcionalmente, uma maior participação dos servidores (70,6\%). Em relação às condições de saúde, os celetistas apresentaram maiores queixas referentes a problemas respiratórios (52,5\%); e os servidores, questões do aparelho circulatório (25,6\%). Considera-se igualar não só os instrumentos, mas a qualidade da avaliação para os trabalhadores celetistas, melhorando os dados para propor ações de promoção.

PALAVRAS-CHAVE Saúde do trabalhador. Exames médicos. Setor público. Serviços de saúde do trabalhador.

ABSTRACT The study aims to present the health profile of employees of a federal production unit that underwent the periodic health examinations. It is a descriptive and exploratory study, which analyzed 503 occupational medical records. There was balanced participation by gender and, proportionally, a greater participation of public servants (70.6\%). Regarding health conditions, the CLT (Consolidation of Labor Laws) employees had the biggest complaints related to respiratory problems (52.5\%) and the servants, circulatory system issues (25.6\%). It is considered to match not only the instruments, but the quality of assessment for CLT employees, improving the data to propose promotion actions.

KEYWORDS Occupational health. Medical examination. Public sector. Occupational health services. 


\section{Introdução}

O trabalho é compreendido como uma atividade fundamental do homem. Com a efetivação do modo de produção capitalista, observam-se profundas e constantes transformações sociais, sendo um dos espaços privilegiados dessas mudanças a esfera produtiva. Assim, o processo da saúde/doença, por meio da exposição diferenciada aos riscos à saúde, terá uma associação com a forma de organização social da produção.

Nesse sentido, ao se considerar a centralidade do trabalho na vida cotidiana e as transformações que o chamado 'mundo do trabalho' vem sofrendo ao longo dos séculos, com as mudanças conjunturais e avanços tecnológicos, pode-se observar que o campo da saúde também apresentará reflexos desse contexto, em especial devido ao seu papel para o controle da força de trabalho.

Quando se destaca a realidade brasileira, Faleiros (1992) pontua que o Estado brasileiro, no que tange à intervenção nas questões de saúde e segurança do trabalhador, traduz-se mais em compensações do desgaste que em mudança das condições de trabalho. Nesse cenário, os trabalhadores

[...] não têm o controle de seu corpo, das condições de trabalho, da definição de doenças profissionais, dos perigos inerentes à produção e nem possuem a informação e o saber sobre os riscos das suas atividades. (CAVALCANTI, 2011, P. 166).

A característica original da doutrina do direito trabalhista que norteia até hoje o estabelecimento da regra é a prevenção do desgaste da força de trabalho, de modo a evitar a ocorrência de situações capazes de impedir o trabalho. Embora seja diretamente vinculada à questão da saúde, na perspectiva da regra a ideia de desgaste da força de trabalho é a perda da capacidade, de aptidão, da condição, do vigor, da força, ou da perda de tudo isso combinado, sem entrar no mérito do entendimento do que seja saúde. (VASCONCELLOS, 2011, P. 131).

A legislação trabalhista, no ano de 1978, implementou as chamadas Normas Regulamentadoras (NRs) e, entre elas, a NR $\mathrm{n}^{0} 7$, que

[...] estabelece a obrigatoriedade de elaboração e implementação, por parte de todos os empregadores e instituições que admitam trabalhadores como empregados, do Programa de Controle Médico de Saúde Ocupacional (PCMSO). (BRASIL, 1978, P. 1).

O PCMSO apresenta como objetivo a promoção e preservação da saúde do conjunto dos trabalhadores e inclui, entre outras atribuições, a realização obrigatória dos Exames Médicos Periódicos (EMPs). Tais exames são compostos de: uma avaliação clínica e exames complementares, realizados de acordo com os termos específicos da NR e seus anexos. A periodicidade está relacionada com a atividade desenvolvida e com o risco ocupacional a que os trabalhadores estão submetidos, além de com a idade.

No âmbito do Serviço Público Federal, somente em 2009, por meio do Subsistema Integrado de Assistência ao Servidor Público Federal (Siass) com algumas características similares ao proposto pela NR 07 - os exames periódicos tornaram-se obrigatórios e foram normatizados para os servidores públicos federais, por intermédio do Decreto $\mathrm{n}^{\mathrm{O}} 6.856$, de 25 de maio de 2009, Art. $2^{\circ}$ :

A realização de exames médicos periódicos tem como objetivo, prioritariamente, a preservação da saúde dos servidores, em função dos riscos existentes no ambiente de trabalho e de doenças ocupacionais ou profissionais. (BRASIL, 2009B).

A prática dos EMPs é intrinsicamente vinculada à Saúde Ocupacional (SO); porém 
não há impeditivos normativos para que, em sua execução, outros elementos sejam utilizados visando uma avaliação mais integral do quadro de saúde dos trabalhadores, tais como conceitos do campo da Saúde do Trabalhador (ST), seja ao realizar a intervenção, seja ao analisar os dados gerados pelos EMP.

A saúde do trabalhador busca compreender melhor a determinação do processo saúde-doença nos trabalhadores e desenvolver alternativas de intervenção que levem a transformação da realidade, em direção à apropriação pelos trabalhadores da dimensão humana do trabalho. [...] A atuação em saúde do trabalhador está baseada na premissa de que os trabalhadores apresentam um viver, adoecer e morrer compartilhado com o conjunto da população, em um dado tempo, lugar e inserção social, mas que é, também, específico, resultante de sua inserção em um processo de trabalho particular. E esta especificidade dever ser contemplada pelos serviços de saúde. (DIAS, 1996, P. 28).

Assim, partindo de premissas da ST, os EMP podem torna-se Exames Periódicos de Saúde (EPS), em que a avalição não se restrinja somente à anamnese médica, mais que outros saberes sejam incorporados a essa prática de saúde e que possuam um olhar interprofissional para as questões saúde/ trabalho; uma vez que a ST traz consigo o desenvolvimento de alternativas de intervenção, buscando, portanto, estabelecer causas de agravos à sua saúde, reconhecer seus determinantes, estimar riscos, dar a conhecer os modos de prevenção e promover saúde (MENDES; DIAS, 1991).

A incorporação de conhecimentos da Medicina do Trabalho e da Saúde Ocupacional, a aplicação das normas limitadas da Higiene e Segurança do Trabalho fazem parte desse trajeto, numa perspectiva permanente de definição de marcos conceituais e práticas que exprimam uma visão totalizante do ser humano em sua relação com o trabalho. (GOMEZ-MINAYO; THEDIM-COSTA, 1997, P. 26).

Nessas perspectivas, aos serviços que cuidam da saúde dos trabalhadores, seja por intermédio da NR ou do Siass, não há uma determinação normativa que deva seguir um modelo especifico de ficha ocupacional, permitindo que a adequem à realidade laboral de seus trabalhadores.

Logo, o objetivo deste artigo é apresentar o perfil de saúde dos trabalhadores de unidade federal de produção que realizaram os EPS, no ciclo 2013/14, por meio da ficha ocupacional - elaborada coletivamente entre os serviços de ST da instituição para a realização dos EPS pela equipe multiprofissional (medicina do trabalho, enfermagem, psicologia e serviço social).

\section{Métodos}

Este artigo resulta de um estudo de caso realizado em uma unidade federal produtora de imunobiológicos, cuja força de trabalho, ao final de 2014, era de 1.547 trabalhadores, agregando três vínculos: $18 \%$ de servidores públicos federais (regidos pelo RJU Regime Jurídico Único), 78\% prestadores de serviços (regidos pela CLT - Consolidação das Leis do Trabalho) e $4 \%$ bolsistas.

Colaborou para essa escolha a inserção da unidade no atual modelo flexível de produção atuando com metas e indicadores, além de contar com uma força de trabalho diversificada que, conforme necessidade da demanda, é remanejada de outros setores da mesma área ou de outras áreas para atender aos prazos; ou efetua contratações pontuais (por tempo determinado) para auxiliar na produção ou efetuar consultorias específicas.

A unidade é dividida em cinco áreas organizacionais, duas com atribuições eminentemente administrativas e três vinculadas às rotinas de produção: a) Desenvolvimento: promove o desenvolvimento de vacinas, 
reativos para diagnóstico e biofármacos; b) Qualidade: realiza os testes, assegura o controle de qualidade e liberação de lotes produzidos, conforme preconizado pelas normas de boas práticas de fabricação; c) Produção: realiza todo processamento final das vacinas e reativos, além da rotulagem e embalagem destes e dos biofármacos. Possui trabalho noturno e por plantão, de modo que essa área funciona 24 horas.

As áreas de Desenvolvimento, Qualidade e Produção realizam suas atividades em ambiente laboratorial, com temperatura e circulação controladas; seguindo normas nacionais e internacionais de boas práticas de fabricação. Assim, são diversos processos que obedecem uma rotina programada e com atividades repetitivas. São áreas cujo processo de trabalho mescla interação com máquinas de alta tecnologia e atividades que ainda remetem ao modelo fordista/taylorista de organização da produção - como na linha de montagem dos kits, envase de diluentes ou embalagem das vacinas.

As demais áreas (Direção e Gestão) apresentam rotinas administrativas realizadas em ambiente predominantemente de escritório; com exceção da área de armazenagem, onde há as atividades de carga e descarga de produtos, equipamento, insumos, entre outros - que requer maior esforço físico por parte dos trabalhadores.

Optou-se pelo estudo de caso, visto que

é útil para gerar conhecimento sobre características significativas de eventos vivenciados, tais como intervenções e processos de mudança. (MINAYO, 2014, P. 164).

Utilizou-se como abordagem metodológica a pesquisa qualitativa e, complementarmente, dados quantitativos visto que ambos os dados não se opõem: "Ao contrário, se complementam, pois, a realidade abrangida por eles interage dinamicamente, excluindo qualquer dicotomia" (MINAYO, 1999, P. 22).

Também há um caráter descritivo e exploratório a respeito do estudo. Segundo Tobar e Yalour (2001, P. 69), um estudo descritivo "[...] expõem características de determinada população ou determinado fenômeno". Em relação aos estudos exploratórios, os mesmos autores destacam que ocorrem "[...] em áreas e sobre problemas dos quais há escasso ou nenhum conhecimento acumulado e sistematizado".

A unidade tem sob sua responsabilidade a execução dos EPS para os servidores e bolsistas e o monitoramento (conforme seu PCMSO) dos EPS para os prestadores de serviço. Assim, a definição do grupo de trabalhadores para elaboração do perfil foi precedida de um levantamento preliminar, mediante informações do banco de dados sobre os EPS do setor de saúde, a fim de verificar quantitativo de trabalhadores - separados por vínculos, que compareceram às avaliações no ciclo 2013/2014. Nesse sentido, dos 889 trabalhadores elegíveis para realizarem a avaliação dos EPS, 503 compareceram, sendo 332 celetistas e 171 servidores.

Ressalta-se que, neste ciclo (2013/14), o setor adotou uma nova ficha ocupacional para avaliação da saúde dos servidores, a qual também foi adotada para coleta de dados sobre a saúde dos prestadores de serviço. Foram excluídos da pesquisa aqueles trabalhadores sem o período aquisitivo para a realização da avaliação (contratados ou empossados a partir de janeiro de 2013) e os bolsistas (visto que encontraram-se dados referentes somente ao admissional e também devido à temporariedade do vínculo dois anos).

Cabe destacar que, nesse ciclo, o primeiro momento da avaliação dos EPS foi similar para os trabalhadores de todos os vínculos; ou seja, ao responderem à convocação do setor de saúde com a data do exame, apresentavam-se ao setor e recebiam a ficha ocupacional para preenchimento das questões de saúde e estilo de vida. As etapas seguintes dos EPS são diferenciadas conforme vínculo, por isso não foram consideradas para a elaboração do perfil; isto é, só foram 
utilizados dados informados somente pelos trabalhadores.

O trabalho de campo iniciou-se após avaliação e autorização do Comitê de Ética em Pesquisa da Escola Nacional de Saúde Pública Sergio Arouca (Ensp/Fiocruz), por meio do parecer $\mathrm{n}^{\mathrm{o}}$ 1.010.308/2015; bem como da unidade onde foi realizado o trabalho de campo de acordo com a legislação e normativas vigentes.

\section{Instrumento de coleta de dados}

A fim de obter um melhor aproveitamento da ficha ocupacional, foi elaborada uma planilha de Excel $^{\circledR}$ com os seguintes eixos e variáveis:

1) Identificação: Área; vínculo; idade; sexo; tempo de empresa e cargo (em relação à escolaridade).

2) Questões de saúde e fatores de risco: Hipertensão; problemas cardíacos; problemas respiratórios; problemas renais; problemas hepáticos; diabetes; problema gastrointestinal; problemas de visão; problemas de saúde mental; doença vascular; alergia; problemas osteomusculares; problemas reumatológicos; colesterol e triglicerídeos alterados; acima do peso; sedentarismo; tabagismo e consumo de bebida alcoólica.

3) Saúde mental: Estresse; insônia; SRQ20 e suporte (medicação controlada, terapia e/ ou médica).

4) Desconforto físico (Diagrama de Corllet): Pescoço; cervical; costa superior; costa médio; costa inferior; bacia; ombro; braço; cotovelo; antebraço; punho; mão; coxa e perna.

Salienta-se que, para aferir as questões de saúde mental, além da pergunta que consta na primeira folha da ficha ocupacional, existe um outro bloco no qual o trabalhador assinala ouras questões que podem ser associadas à saúde mental (estresse, insônia) e se tem suporte psiquiátrico, seja por meio de medicação controlada ou acompanhamento médico especializado; além do preenchimento do chamado Self Report Questionnaire (SRQ-20), um compilado de 20 questões com respostas dicotômicas ( $\operatorname{sim} /$ não) sobre sintomas físicos e psicoemocionais para rastrear transtornos mentais comuns. O escore para cada resposta afirmativa, pontua-se com o valor 1; e o ponto de corte para suspeição (presença ou ausência) dos transtornos mentais não psicóticos utilizado é de oito (GOUGET, 2014).

Em relação à aferição do desconforto postural que pode auxiliar no diagnóstico de doenças osteomusculares, o setor usa o diagrama proposto por Corllet e Manenica (1980) que divide o corpo humano em diversos segmentos, em que o trabalhador assinala na figura que representa o corpo humano os segmentos em que sente dores ou desconforto. A escala de intensidade do desconforto/ dor é classificada em 5 níveis, que variam de 1, para 'nenhum desconforto/dor', até 5 , 'intolerável desconforto/dor'.

\section{Resultados e discussão}

Conforme apresentado na tabela 1, participaram da avaliação 503 trabalhadores: 70,66\% de servidores e $37,34 \%$ de terceirizados, que realizaram a avaliação no setor de saúde da unidade. Havendo um equilíbrio na participação por gênero - similar à proporção geral dos trabalhadores da unidade -, sendo 51,3\% do sexo masculino e $48,7 \%$ do sexo feminino; porém, ao se verificar por vínculo, a participação feminina foi maior entre os RJUs (59\%), enquanto a masculina foi maior entre os celetistas (57\%). Em relação à escolaridade vinculada ao cargo, houve um predomínio de trabalhadores de nível superior (57,7\%) no geral e para ambos os vínculos. 
Tabela 1. Características sociofuncionais dos participantes dos EPS conforme vínculo

\begin{tabular}{|c|c|c|c|c|c|c|}
\hline \multirow{2}{*}{ Variáveis } & \multicolumn{2}{|c|}{ RJU } & \multicolumn{2}{|c|}{ CLT } & \multicolumn{2}{|c|}{ Ambos } \\
\hline & $\mathrm{N}$ & $\%$ & $\mathrm{~N}$ & $\%$ & $\mathrm{~N}$ & $\%$ \\
\hline & 171 & & 332 & & 503 & \\
\hline \multicolumn{7}{|l|}{ Gênero } \\
\hline Feminino & 101 & 59,06 & 144 & 43,37 & 245 & 48,7 \\
\hline Masculino & 70 & 40,94 & 188 & 56,63 & 258 & 51,3 \\
\hline \multicolumn{7}{|c|}{ Cargo por nível de escolaridade } \\
\hline Nível médio & 57 & 33,33 & 156 & 46,99 & 213 & 42,3 \\
\hline Nível Superior & 114 & 66,67 & 176 & 53,01 & 290 & 57,7 \\
\hline \multicolumn{7}{|l|}{ Faixa etária } \\
\hline De 18 a 30 anos & 19 & 11,11 & 66 & 19,88 & 85 & 16,90 \\
\hline De 31 a 40 anos & 52 & 30,41 & 126 & 37,95 & 178 & 35,39 \\
\hline De 41 a 50 anos & 55 & 32,16 & 91 & 27,41 & 146 & 29,03 \\
\hline De 51 a 60 anos & 36 & 21,05 & 40 & 12,05 & 76 & 15,11 \\
\hline 61 anos ou mais & 9 & 5,26 & 9 & 2,71 & 18 & 3,58 \\
\hline \multicolumn{7}{|l|}{ Tempo de Serviço } \\
\hline De 1 a 3 anos & 43 & 25,15 & 168 & 50,60 & 211 & 41,95 \\
\hline De 4 a 10 anos & 55 & 32,16 & 92 & 27,71 & 147 & 29,22 \\
\hline De 11 a 20 anos & 42 & 24,56 & 70 & 21,08 & 112 & 22,27 \\
\hline De 21 a 30 anos & 19 & 11,11 & 0 & 0,00 & 19 & 3,78 \\
\hline 31 anos ou mais & 12 & 7,02 & 2 & 0,60 & 14 & 2,78 \\
\hline
\end{tabular}

Fonte: Elaboração própria.

Entre as questões de saúde (tabela 2) assinaladas pelos trabalhadores que participaram dos EPS, verificou-se que predominam os problemas respiratórios (bronquite, asma, rinite, tosse crônica, sinusite) $-49 \%$; seguidos pelos problemas osteomusculares (doenças da coluna, dor nas costas, dores nas articulações) - $43,5 \%$ - e problemas na visão - $43 \%$.

Compilados dessa maneira, os resultados fogem um pouco dos dados da Organização Mundial da Saúde (OMS), nos quais se destaca que as Doenças Cardiovasculares (DCV) foram responsáveis por 30\% de mortalidade nas últimas décadas (SIMÃO ET AL., 2013), ou dos da previdência social, que citam as DCV, osteomusculares e de saúde mental como as de maiores causas de afastamentos ou de mortalidade (BRASIL, 2015).
Segundo a Sociedade Brasileira de Cardiologia, os principais fatores de risco para DCV são: hipertensão arterial, tabagismo, obesidade/sobrepeso; dislipidemia; diabetes; síndrome metabólica, fatores psicossociais e sedentarismo. Todavia, devido ao tipo de cage utilizado na ficha ocupacional para avaliar as questões vinculadas ao estilo de vida (sedentarismo, estar acima do peso, consumo de bebida alcoólica e cigarro), optou-se por apresentar somente os dados; pois seriam necessárias outras informações para tratar como fatores de risco associados para as DCV.

Quando se realiza o desmembramento por vínculo, observa-se que as questões de saúde entre os trabalhadores celetistas são similares ao resultado total; entretanto, 
para os servidores públicos, predominam os problemas osteomusculares $(52,6 \%)$, seguidos dos problemas na visão (52\%) e dos problemas respiratórios (45\%). Em relação ao gênero, entre as mulheres há o predomínio dos problemas respiratórios
(56\%), seguidos dos osteomusculares (53\%) e dos problemas na visão (44\%); já entre os homens, também predominam as questões respiratórias (43\%), seguidas dos problemas na visão (42\%) e osteomusculares $(34,5 \%)$.

Tabela 2. Prevalência de morbidades e questões sobre estilo de vida referida pelos trabalhadores, conforme vínculo e gênero, que participaram dos EPS, no ciclo 2013-2014

\begin{tabular}{|c|c|c|c|c|c|c|c|c|c|c|}
\hline \multirow{2}{*}{ Variáveis } & \multicolumn{2}{|c|}{ RJU } & \multicolumn{2}{|c|}{ CLT } & \multicolumn{2}{|c|}{ Fem } & \multicolumn{2}{|c|}{ Masc } & \multicolumn{2}{|c|}{ Ambos } \\
\hline & $\mathrm{N}$ & $\%$ & $\mathrm{~N}$ & $\%$ & N & $\%$ & $\mathrm{~N}$ & $\%$ & N & $\%$ \\
\hline Questões de Saúde & 171 & $100 \%$ & 332 & $100 \%$ & 245 & $100 \%$ & 258 & $100 \%$ & 503 & $100 \%$ \\
\hline Hipertensão & 43 & 25,15 & 75 & 22,59 & 54 & 22,04 & 64 & 24,81 & 118 & 23,46 \\
\hline Problemas Cardíacos & 25 & 14,62 & 30 & 9,04 & 33 & 13,47 & 22 & 8,53 & 55 & 10,93 \\
\hline Problemas Respiratórios & 77 & 45,03 & 171 & 51,51 & 138 & 56,33 & 110 & 42,64 & 248 & 49,3 \\
\hline Problemas Renais & 15 & 8,77 & 24 & 7,23 & 17 & 6,94 & 22 & 8,53 & 39 & 7,75 \\
\hline Problemas Hepáticos & 12 & 7,02 & 13 & 3,92 & 12 & 4,90 & 13 & 5,04 & 25 & 4,97 \\
\hline Diabetes & 13 & 7,6 & 7 & 2,11 & 5 & 2,04 & 15 & 5,81 & 20 & 3,98 \\
\hline Problemas Gastrointestinais & 48 & 28,07 & 63 & 18,98 & 60 & 24,49 & 51 & 19,77 & 111 & 22,07 \\
\hline Infecções no Ouvido & 8 & 4,68 & 11 & 3,31 & 10 & 4,08 & 9 & 3,49 & 19 & 3,78 \\
\hline Problemas na visão & 89 & 52,05 & 126 & 37,95 & 107 & 43,67 & 108 & 41,86 & 215 & 42,74 \\
\hline Questões de Saúde Mental & 10 & 5,85 & 8 & 2,41 & 10 & 4,08 & 8 & 3,10 & 18 & 3,58 \\
\hline Doença Vascular & 62 & 36,26 & 61 & 18,37 & 86 & 35,10 & 37 & 14,34 & 123 & 24,45 \\
\hline Alergias & 45 & 26,32 & 93 & 28,01 & 89 & 36,33 & 49 & 18,99 & 138 & 27,44 \\
\hline Problemas Osteomusculares & 90 & 52,63 & 129 & 38,86 & 130 & 53,06 & 89 & 34,50 & 219 & 43,54 \\
\hline Problemas Reumatológicos & 16 & 9,36 & 11 & 3,31 & 15 & 6,12 & 12 & 4,65 & 27 & 5,37 \\
\hline $\begin{array}{l}\text { Colesterol e Triglicerídeos } \\
\text { elevados }\end{array}$ & 32 & 18,71 & 65 & 19,58 & 43 & 17,55 & 54 & 20,93 & 97 & 19,28 \\
\hline Acima do peso & 87 & 50,88 & 140 & 42,17 & 104 & 42,45 & 123 & 47,67 & 227 & 45,13 \\
\hline Sedentarismo & 83 & 48,54 & 152 & 45,78 & 119 & 48,57 & 116 & 44,96 & 235 & 46,72 \\
\hline Fuma & 14 & 8,19 & 15 & 4,52 & 11 & 4,49 & 18 & 6,98 & 29 & 5,77 \\
\hline Consome bebida Alcoólica & 82 & 47,95 & 154 & 46,39 & 99 & 40,41 & 137 & 53,10 & 236 & 46,92 \\
\hline
\end{tabular}

Fonte: Elaboração própria.

Ao agrupar os dados do perfil conforme os grupos do código internacional de doenças (CID-10), verificou-se que os problemas respiratórios (77\%) continuam predominando; porém são seguidos pelas doenças endócrinas (68\%) e do aparelho circulatório (59\%).

Se comparados (tabela 3) os resultados dos EPS com o quantitativo de afastamentos/ licenças médicas da unidade no mesmo período, nota-se a manutenção das questões respiratórias $(21,5 \%)$ como prevalentes, corroborando o perfil, assim como as doenças osteomusculares (18\%). Salienta-se que o item XXI, que estaria em primeiro lugar, não foi considerado por tratar-se de questões sobre o estilo de vida, e não uma morbidade instalada. 
Tabela 3. Comparação entre a prevalência de morbidades aferidas nos EPS e os afastamentos médicos, conforme grupo de CID, no ano de 2013

\begin{tabular}{|c|c|c|c|c|}
\hline \multirow{2}{*}{ Variáveis } & \multicolumn{2}{|c|}{ EPS } & \multicolumn{2}{|c|}{ Licenças } \\
\hline & $\mathrm{N}$ & $\%$ & $\mathrm{~N}$ & $\%$ \\
\hline Grupo de CID & 503 & $100 \%$ & 4.702 & $100 \%$ \\
\hline IV-Doenças endócrinas, metabólicas (E00-E90) & 344 & 68,39 & 30 & 0,64 \\
\hline V-Transtornos mentais e comportamentais (F00- F99) & 18 & 3,58 & 236 & 5,02 \\
\hline VI- Doenças do sistema nervoso (G00-G99) & 131 & 26,04 & 114 & 2,42 \\
\hline VII- Doenças do Olho e anexos (HOO-H59) & 215 & 42,74 & 153 & 3,25 \\
\hline VIII- Doenças do Ouvido e da apófise (H60-H95) & 18 & 3,58 & 95 & 2,02 \\
\hline IX- Doenças do aparelho circulatório (100-199) & 295 & 58,65 & 213 & 4,53 \\
\hline X-Doenças do aparelho respiratório (J00-J99) & 386 & 76,74 & 1010 & 21,48 \\
\hline $\mathrm{XI}$ - Doenças do aparelho digestivo (K00-K93) & 136 & 27,04 & 389 & 8,27 \\
\hline XII- Doenças da Pele e tecido subcutâneo (L00-L99) & 0 & 0,00 & 131 & 2,79 \\
\hline XIII-Doenças do sistema Osteomuscular (M00-M99) & 246 & 48,91 & 837 & 17,80 \\
\hline XIV- Doenças do aparelho Geniturinário (N00-N99) & 39 & 7,75 & 144 & 3,06 \\
\hline XXI - Fatores que influenciam o estado de saúde (Z72) & 443 & 88,07 & 1 & 0,02 \\
\hline
\end{tabular}

Fonte: Elaboração própria.

Consta da ficha ocupacional do EPS a percepção dos riscos informados pelos trabalhadores, que além dos riscos previstos na NR-9, traz algumas questões ergonômicas, porém sem elementos da organização do trabalho sugeridos pela NR-17.

Assim, quando observados os resultados quanto à percepção dos trabalhadores sobre a exposição aos riscos ocupacionais: $65 \%$ informaram realizarem movimentos repetitivos; $53 \%$ possuem risco ergonômico; $52 \%$ teriam exposição ao risco biológico; $50 \%$ aos produtos químicos e $50 \%$ ao esforço visual. Nesse sentido, comparados aos dados da tabela 3 , não se pode afirmar que existe um nexo direto entre as morbidades apresentadas e os riscos ocupacionais; porém tais elementos não devem ser desconsiderados para investigar agravos e propor melhorias os ambientes laborais.

Ressalta-se que, segundo Sivieri (1996, P. 81),

[...] risco é a probabilidade de ocorrência de um evento causador de dano às pessoas e ao meio ambiente de forma leve ou grave, temporária ou permanente, parcial ou total.

Já para Avaliação da Segurança e Saúde Ocupacional - Occupational Health and Safety Assessment Series (OHSAS), risco é: "Combinação da probabilidade de ocorrência e da(s) consequência(s) de um determinado evento perigoso" (OCCUPATIONAL HEALTH AND SAFETY ASSESSMENT SERIES, 1999, P. 9). Cabe destacar que a NR-9 considera riscos ambientais

[...] os agentes físicos, químicos e biológicos existentes nos ambientes de trabalho que, em função de sua natureza, concentração ou intensidade e tempo de exposição, são capazes de causar danos à saúde do trabalhador. (BRASIL, 1977, P. 1).

Sivieri (1996) ainda chama a atenção para o fato de que muitas questões do ambiente industrial e de outros setores produtivos não têm sua origem nos tradicionais fatores físicos, químicos ou biológicos. 
Existem devido às contradições originarias do cotidiano, das relações funcionais, dos conflitos e dos processos psicossociais. $\mathrm{Na}$ complexidade da vida social, situações de trabalho, associadas a sucessivas frustrações e ataques a autoimagem, progressivamente provocam, além do desgaste metafórico da identidade, processos psicossomáticos que geram quadros clínicos de doenças orgânicas graves, como úlceras, hipertensão arterial, gastrite etc., e também distúrbios de ordem psicológica como insônia, ansiedade, depressão estresse etc., situações consideradas de risco, onde o trabalhador fica mais fragilizado, e potencialmente mais exposto a acidentes e mortes. (SIVIERI, 1996, P. 81).

As questões de saúde mental são apontadas em alguns estudos sobre o mundo do trabalho entre as três principais causas de afastamento seja no serviço público, seja na esfera privada. Ao se observar os dados da tabela 1, somente $4 \%$ dos trabalhadores responderam possuir alguma patologia vinculada aos transtornos mentais (estaria em último lugar entre as questões de saúde do perfil).
Contudo, quando se verificou o SRQ-20 (gráfico 1), 41 trabalhadores (8\%) tiveram um escore acima ou igual a 8; ou seja, apresentavam, na ocasião, algum transtorno mental leve (com uma predominância dos trabalhadores celetistas e em relação ao gênero a prevalência do sexo feminino). Já sobre o suporte, 83 trabalhadores $(16,5 \%)$ utilizam medicação controlada ou mantêm tratamento psiquiátrico (havendo pouca diferença entre os vínculos e um predomínio do sexo feminino). Ou seja, há uma discrepância nos dados informados entre a percepção no reconhecimento enquanto portador de alguma patologia de saúde mental e a utilização de algum suporte nessa esfera.

Ao tratar dos outros fatores associados à saúde mental, têm-se $36 \%(n=179)$ de trabalhadores considerando-se estressados ao comparar os vínculos, essa percepção é maior entre os celetistas e por gênero entre as mulheres. Em relação à insônia, $26 \%(n=131)$ assinalaram positivamente para a questão, quase havendo paridade entre os gêneros.

Gráfico 1. Distribuição das questões associadas à saúde mental relacionada aos trabalhadores participantes dos EPS, por vínculo, no ciclo 2013-2014

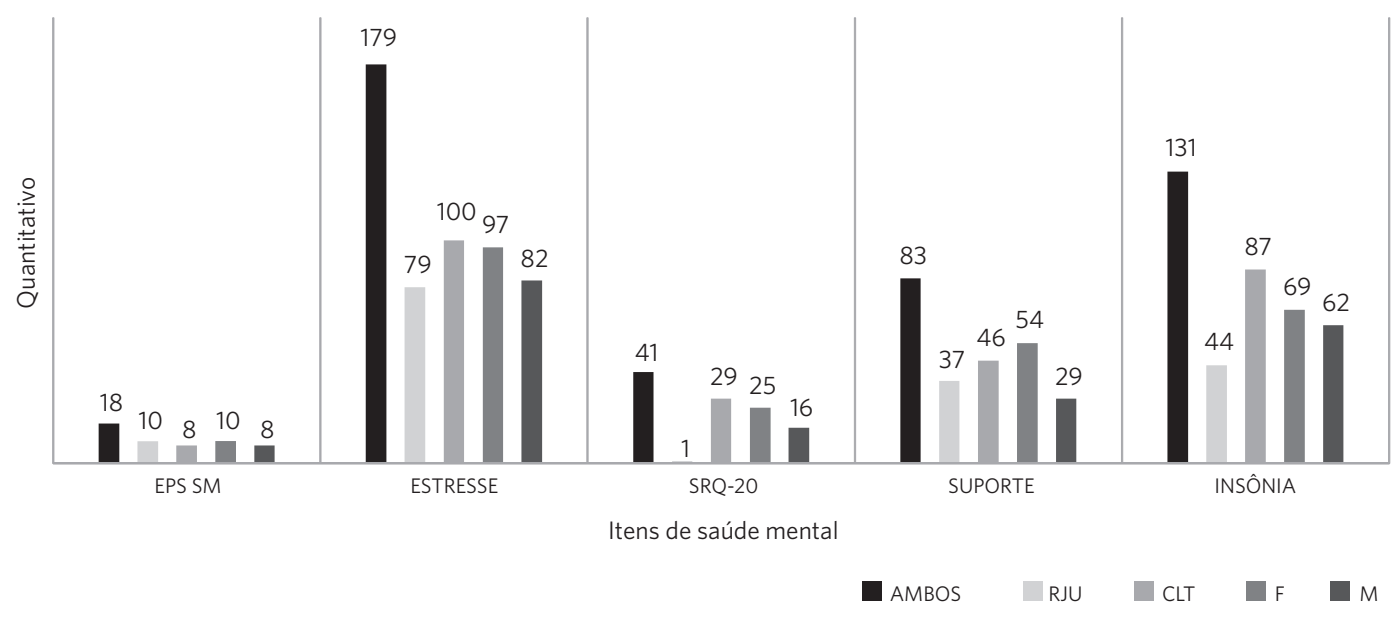


Quando se observa o gráfico 1, não se têm elementos suficientes para informar quais seriam os motivos para a disparidade dos dados e mesmo aparentando, seja pelas informações do EPS, seja pelas informações de absenteísmo, que a unidade estaria fora dos padrões epidemiológicos no que tange às questões de saúde metal, com baixos índices. Entretanto, os dados que a unidade possui sobre a média de dias perdidos com as licenças coloca as morbidades de saúde mental entre as três maiores causas de longos afastamentos: $2013-1.138$ dias $\left(3^{\circ}\right) ; 2014-1.594$ $\operatorname{dias}\left(3^{\circ}\right)$ e $2015-2.306 \operatorname{dias}\left(2^{\circ}\right)$.

Em relação ao último bloco, sobre o desconforto físico (tabela 4), uma vez que não se trata de um estudo ergonômico, optou-se por apresentar os resultados referentes às marcações da escala de intensidade igual ou acima de 3 ('moderado/bastante/intolerável desconforto/dor'), excluindo a escala 1 e 2 ('ausência/ algum') que correspondem, respectivamente, a $13 \%$ e $87 \%$ do quantitativo total.

Observou-se que as maiores queixas são das áreas superiores (pescoço, cervical e costas superiores). Para os celetistas, a maior fonte de desconforto é a região das costas superior (26\%), já para os servidores, é a região cervical (12\%). Em relação ao gênero, $20 \%$ das mulheres queixaram-se da região cervical, e $13 \%$ dos homens da região das costas inferior. A forte presença masculina nas atividades de carga/descarga de produtos e outros processos de maior exigência física pode ter contribuído para essa diferença entre os gêneros.

Tabela 4. Distribuição das queixas dos trabalhadores participantes dos EPS, por vínculo, em relação ao desconforto postural aferido pelo Diagrama de Corllet, no ciclo 2013-2014

\begin{tabular}{|c|c|c|c|c|c|c|c|c|c|c|}
\hline \multirow{2}{*}{$\begin{array}{l}\text { Diagrama de } \\
\text { Corllet }\end{array}$} & \multicolumn{2}{|c|}{$\mathbf{F}$} & \multicolumn{2}{|c|}{ M } & \multicolumn{2}{|c|}{ RJU } & \multicolumn{2}{|c|}{ CLT } & \multicolumn{2}{|c|}{ Total } \\
\hline & $\mathrm{N}$ & $\%$ & $\mathrm{~N}$ & $\%$ & $N$ & $\%$ & $N$ & $\%$ & $N$ & $\%$ \\
\hline Pescoço & 88 & 17,5 & 40 & 8,0 & 51 & 10,1 & 77 & 15,3 & 128 & 25,4 \\
\hline Cervical & 101 & 20,1 & 42 & 8,3 & 59 & 11,7 & 84 & 16,7 & 143 & 28,4 \\
\hline Costas Superior & 50 & 9,9 & 22 & 4,4 & 26 & 5,2 & 132 & 26,2 & 158 & 31,4 \\
\hline Costas Médio & 50 & 9,9 & 40 & 8,0 & 36 & 7,2 & 54 & 10,7 & 90 & 17,9 \\
\hline Costas Inferior & 77 & 15,3 & 64 & 12,7 & 46 & 9,1 & 95 & 18,9 & 141 & 28,0 \\
\hline Bacia & 36 & 7,2 & 21 & 4,2 & 25 & 5,0 & 32 & 6,4 & 57 & 11,3 \\
\hline Ombro & 53 & 10,5 & 25 & 5,0 & 28 & 5,6 & 50 & 9,9 & 78 & 15,5 \\
\hline Braço & 15 & 3,0 & 5 & 1,0 & 10 & 2,0 & 10 & 2,0 & 20 & 4,0 \\
\hline Cotovelo & 15 & 3,0 & 6 & 1,2 & 8 & 1,6 & 13 & 2,6 & 21 & 4,2 \\
\hline Antebraço & 15 & 3,0 & 5 & 1,0 & 7 & 1,4 & 13 & 2,6 & 20 & 4,0 \\
\hline Punho & 44 & 8,7 & 21 & 4,2 & 18 & 3,6 & 47 & 9,3 & 65 & 12,9 \\
\hline Mão & 34 & 6,8 & 12 & 2,4 & 14 & 2,8 & 32 & 6,4 & 46 & 9, \\
\hline Coxa & 10 & 2,0 & 4 & 0,8 & 5 & 1,0 & 9 & 1,8 & 14 & 2,8 \\
\hline Perna & 35 & 7,0 & 12 & 2,4 & 15 & 3,0 & 32 & 6,4 & 47 & 9,3 \\
\hline
\end{tabular}

Fonte: Elaboração própria. 
Nessas perspectivas, ao se apresentar os três blocos da ficha ocupacional utilizada para os EPS, é possível verificar a quantidade de dados gerados e as possibilidades de cruzamentos para refletir sobre os itens que podem ter uma avaliação mais aprofundada. Por exemplo, selecionar os trabalhadores que assinalaram queixas osteomusculares e desconforto postural, com o seu tempo de serviço e a descrição da atividade, pode auxiliar na investigação de doença ocupacional.

Há uma grande quantidade de informações registradas rotineiramente pelos serviços que não são utilizadas nem para a análise da situação de saúde, nem para a definição de prioridades, nem para a reorientação de práticas. Muitas dessas informações obtidas regularmente, se analisadas, podem se constituir em matéria-prima para um processo desejável de avaliação continuada dos serviços, também chamada de monitoramento, ou, num estágio mais avançado de organização dos serviços de saúde. (SILVA; FORMIGLI, 1994, P. 87).

Por fim, usar conceitos do campo da ST para a análise dos dados dos EPS e para avaliar os instrumentos como a ficha ocupacional e a intervenção como um todo é importante; visto que a ST compreende as relações trabalho e saúde-doença por meio da análise da "[...] determinação social do processo saúde-doença, privilegiando o trabalho" (LACAZ, 2007, P. 759). Apreende o trabalhador como ator histórico, agente de mudanças, que

[...] pode intervir e transformar a realidade de trabalho, participando do controle da nocividade; da definição consensual de prioridades de intervenção e da elaboração de estratégias transformadoras [...]. (LACAZ, 2007, P. 760).

Sua ação caracteriza-se por permanente vigilância das condições de trabalho passíveis de causar agravos ou danos à saúde do trabalhador, por meio de práticas que antecipem e evitem os problemas ou funcionem como contraponto às exigências do capital sobre a força de trabalho, no sentido de estabelecer melhores condições de vida e de bem-estar. (DIAS; NEHMY 2010, P. 15).

\section{Conclusões}

O conhecimento sobre as condições de saúde dos trabalhadores é um importante indicador para que os empregadores, tanto na esfera pública quanto privada, adotem medidas de promoção e prevenção para, se não solucionar, ao menos contribuir para a melhoria da condição de saúde de sua força de trabalho; ou mesmo atuar de modo que a esfera laboral não agrave os quadros de saúde já instaurados e nem crie novos.

Nesse sentido, os EPS permitem que periodicamente os empregadores tenham esse mapeamento epidemiológico e com tais informações possam realizar ações preventivas para todos os seus trabalhadores ou grupos específicos (por atividades, por locais de trabalho), ou reavaliar processos e condições de trabalho. Principalmente, se esses dados dos EPS puderem ser trabalhados e comparados com outros como absenteísmo interno e de outras instituições com processos de trabalho similares.

Em instituições que possuem vínculos diferenciados de contratação, é importante que os trabalhadores tenham os mesmos instrumentos de avaliação de sua saúde, uma vez que estão submetidos às mesmas regras institucionais e aos mesmos processos e condições de trabalho. Dessa forma, a instituição terá dados mais completos e fidedignos para pensar suas ações, em especial, para atuar na melhoria dos processos e ambientes de trabalho que possam trazer prejuízo à saúde dos trabalhadores.

Agregar outros elementos (com cages validados para questões de saúde mental, ergonomia, questões de estilo de vida, DCV, condições de trabalho etc.) e outros 
profissionais permite que se tenha uma avaliação mais ampla sobre a ST, além de possibilitar aferir a eficiência das ações de promoção/ prevenção que o empregador realiza.

Por fim, os EPS podem ser também um canal para efetiva participação dos trabalhadores, especialmente, se os dados consolidados pelos EPS forem restituídos de forma coletiva aos trabalhadores para que possam discuti-los entre si, nos seus setores, com seus representantes (sindicatos, Cipa - Comissão Interna de Prevenção de Acidentes, outros) e/ou com os técnicos dos serviços de saúde e segurança; para refletirem não só sobre sua situação de saúde, mas também sobre o processo e ambiente de trabalho, a fim de auxiliarem na proposição de melhorias e transformação de ambiente laboral.

\section{Referências}

BRASIL. Anuário estatístico da previdência social AEPS 2015. Brasília, DF: Ministério da Fazenda, 2015. Disponível em: <http://www.previdencia.gov.br/wp-content/uploads/2015/08/AEPS-2015-FINAL.pdf>. Acesso em: 23 fev. 2017.

Decreto $\mathrm{n}^{0} 6.833$, de 29 de abril de 2009.

Institui o Subsistema Integrado de Atenção à Saúde do Servidor Público Federal - SIASS e o Comitê Gestor de Atenção à Saúde do Servidor. Diário Oficial [da] União, Brasília, DF, 30 abr. 2009a. Disponível em: <http:// www.planalto.gov.br/ccivil_03/_ato2007-2010/2009/ decreto/d6833.htm>. Acesso em: 23 fev. 2017.

Decreto $\mathrm{n}^{0}$ 6.856, de 25 de maio de 2009. Regulamenta o art. 206-A da Lei no 8.112, de 11 de dezembro de 1990 - Regime Jurídico Único, dispondo sobre os exames médicos periódicos de servidores. Diário Oficial [da] União, Brasília, DF, 26 maio 2009b. Disponível em: <http://www.planalto.gov.br/ ccivil_03/_ato2007-2010/2009/decreto/d6856.htm>. Acesso em: 20 jun. 2013.

NR 7: programa de controle médico de saúde ocupacional. Brasília, DF: MTE, 2013. Disponível em: <http://www.mtps.gov.br/images/Documentos/SST/
NR/NR7.pdf>. Acesso em: 22 abr. 2013.

CAVALCANTI, C. P. N. A intervenção histórica nas relações saúde e trabalho no Brasil: a centralidade da noção do risco na lógica da reparação dos 'infortúnios'. In: __ Cadernos do curso de capacitação em promoção e vigilância em saúde do trabalhador Pass-Siass. Rio de Janeiro: UFRJ; Unirio, 2011, p. 155-170.

CASTIEL, L. D. Os riscos e as loucuras dos discursos da razão no campo da prevenção. Cadernos IHU ideias, São Leopoldo, v. 11, n. 188, jun. 2013.

CORLETT, E. N.; MANENICA, I. The effects and measurement of working postures. Applied Ergonomics, London, v. 11, n. 1, p. 7-16, mar. 1980.

DIAS, E. C. Saúde do Trabalhador. In: TODESCHINI, R. (Org.). Saúde, Meio Ambiente e Condições de Trabalho: Conteúdos Básicos para uma Ação Sindical. São Paulo: Fundacentro, p. 27-35, 1996.

DIAS, E. C.; NEHMY, R. M. Q. Os caminhos da Saúde do Trabalhador: para onde apontam os sinais? Revista médica de Minas Gerais, Belo Horizonte, v. 20, supl. 2p. 13-23, 2010. 
GOMEZ-MINAYO, C.; THEDIM-COSTA, S. M. A construção do campo da saúde do trabalhador: percursos e dilemas. Caderno de saúde pública, Rio de Janeiro, v. 13, n. 2 , p. $21-32,1997$

FALEIROS, V. P. O trabalho da política: saúde e segurança dos trabalhadores. São Paulo: Cortez, 1992.

GOUGET, L. L. D. A aplicação do SRQ-20 como instrumento de levantamento de indicativo de transtorno mental comum. 2014. 30 f. Trabalho de Conclusão de Curso (Especialização de Gestão em Saúde Púbica) - Escola Nacional de Saúde Pública Sergio Arouca, Fundação Oswaldo Cruz, Rio de Janeiro, 2014.

LACAZ, F. A. C. O campo saúde do trabalhador: resgatando conhecimentos e práticas sobre as relações trabalho-saúde. Caderno de saúde pública, Rio de Janeiro, v. 23 , n. 4 , p. $757-766$, abr. 2007.

MENDES, R.; DIAS, E. C. Da Medicina do trabalho à saúde do trabalhador. Revista de saúde pública, Rio de Janeiro, v. 25, n. 5, p. 341-349, 1991.

MINAYO, M. C. S. (Org.). O desafio do conhecimento: pesquisa qualitativa em saúde. São Paulo: Hucitec, 2014.

MCCOY, K. et al. Health promotion in small business: a systematic review of factors influencing adoption and effectiveness of worksite wellness programs. Journal occupational environ medical, Illinois, v. 56, n. 6, p. 579587, jun. 2014.

SATO, L. et al. A saúde mental relacionada ao trabalho e os desafios aos profissionais da saúde. Revista brasileira de saúde ocupacional, São Paulo, v. 36, n. 123, p. 118-127, 2011.

SILVA, L. M. V.; FORMIGLI, V. L. A. Avaliação em saúde: limites e perspectivas. Cadernos de saúde pública, Rio de Janeiro, v. 10, n. 1, p. 80-91, jan./mar. 1994.
SIMÃO, A. F. et al. I Diretriz Brasileira de Prevenção Cardiovascular. Arquivo Brasileiro de Cardiologia, Rio de Janeiro, v. 101, n. 6, Supl. 2, dez. 2013. Disponível em: <http://publicacoes.cardiol.br/consenso/2013/ Diretriz_Prevencao_Cardiovascular.pdf $>$. Acesso em: 23 fev. 2015.

SIVIERI, L. H. Saúde no trabalho e mapeamento de riscos. In: TODESCHINI, R. (Org.). Saúde, meio ambiente e condições de trabalho: conteúdos básicos para uma ação sindical. São Paulo: CUT/Fundacentro, 1996. p. $75-111$.

OCCUPATIONAL HEALTH AND SAFETY ASSESSMENT SERIES. Sistemas de gestão de segurança e saúde ocupacional: especificação. [s.1.]: OHSAS, 1999.

TOBAR, F.; YALOUR, M. R. Como fazer teses em saúde pública: conselhos e ideias para formular projetos $\mathrm{e}$ redigir teses e informes de pesquisas. Rio de Janeiro: Fiocruz, 2001.

VASCONCELLOS, L. C. F. A Imperfeição da regra trabalhista referente à saúde: da revolução industrial à consolidação das leis do trabalho. In: VASCONCELLOS, L. C. F.; OLIVEIRA, M. H. B. (Org.). Trabalho, saúde e direito: uma trajetória crítica e a crítica de uma trajetória. Rio de Janeiro: Educam, 2011a, p. 125-165.

VASCONCELLOS, L. C. F.; AGUIAR, L. A gestão do Sistema Único de Saúde e a Saúde do Trabalhador: o direito que se tem e o direito que se perde. Saúde debate, Rio de Janeiro, v. 39, n.106, p. 830-840, jul./set., 2015.

Recebido para publicação em agosto de 2016

Versão final em dezembro de 2016

Conflito de interesses: inexistente

Suporte financeiro: não houve 